\title{
RESENHA/ REVIEW
}

Silva, F.L. da \& Moura, H.M de M. (orgs.) (2000) 0 Direito à Fala. A QuestãodbPreconeitoLing̈̈́stico Florianópolis: Insular, 128p.

Resenhado por/by Edair M aria G ORSK I (UnivesidadeFederal deSantaCatanina)

\section{Palavras-chave:Preconcitoling̈̈ístico, Idedoga; Podk, Divesidade}

Key-words:Lingisticprgudice, Idedogy; Power, Divesity.

Trata-se de uma coletânea organizada em torno de um assunto polê mico e bastante atual: o preconceito lingüístico. Basta acompanhar, por exemplo, as inúmeras preleções de cunho normativista (observadas em diversos âmbitos) centradas no que é "certo" e "errado" na língua e a conseqüente avaliação social que atribui prestígio ou estigma às diferentes falas, ou as discussões travadas em torno da linguagem politicamente correta, para se constatar o caráter polêmico do tema. Por outro lado, a atualidade do assunto évisível na recorrência com quetem sido abordado sob diferentes ângulos, conforme atestam algumas publicações, como a de Bagno (1999), o documento sobre Definiçãoda Pdítica Lingüística no Brasil resultante de ampla discussão entre os lingüistas e publicado no Bdetimda ABRALIN, 23(1999); o BdetimdaALAB44(2000) sobre o PrgitodeLè contra os Estranginismos bem como matérias em jornais a exemplo de Faraco (2001) na Fdha deS.Paulo entre outras.

O bjetivando estender o debate a um público mais amplo, numa linguagem acessível e "sem o peso da argumentação acadêmica", como bem apontam os organizadores na introdução do livro, 0 direitoà fala surge oportunamente num momento em que se testemunha o sucesso de "novos gramáticos mediatizados" e em que ganha "nova relevância o poder simbólico da linguagem" (p.10). Contendo dez trabalhos que refletem com seriedade diferentes leituras do preconceito lingüístico, a obra se propõe 
intervencionista, colocando, de maneira instigante, resultados da pesquisa em diversas áreas da linguagem a serviço do direito à expressão, com respeito às falas que os grupos construíram ao longo da história. Os organizadores apresentam, com el egância, o conjunto dos artigos, tecendo a trama que interliga os diferentes textos, recobertos por uma mesma temática que pode ser resumida como: crítica à idéia de unidade nacional alicerçada numa língua idealizada pura eúnica.

$\mathrm{N} 0$ artigo de abertura, intitulado A prosa deLima Bameta oquequer essa língua?, Cláudio Cruz, num estilo leve e despojado, refere-se aos, assim chamados por ele, "três moleques do Segundo Reinado" - M achado de A ssis, Cruz e Sousa e Lima B arreto (p.20), reunidos pela característica comum de, negros, terem sido apadrinhados por famílias nobres e, conseqüentemente, terem tido acesso a uma formação superior. N ão obstante esse traço de aproximação, o autor opõe Lima Barreto aos demais escritores, em razão do uso peculiar que aquele faz da língua portuguesa, considerado à época como incorreto, e só mais tarde visto como inserido, com estilo, no contexto cultural, por buscar falar a língua do povo e não retratar a linguagem dominante do período. Esse fato particulariza a obra do romancista, caracterizando-a como de "militância literária" lingüística, daí sua importância no que se refere à questão do preconceito lingüístico. Cruz convoca o leitor a, sem demora, procurar entender a questão da língua na obra do autor de Recrobaçess dbescivãoIsaías Caminhae de TristeFim dePdicanpoQuarema (cujo conjunto parece trazer "uma espécie de bombarelógio que só agora começa a ser detonada"), especialmente nesse momento em que, conforme vislumbra o ensaista, presenciamos o início da implosão da idéia de um espaço literário nacional e único, quando outras línguas buscam expressão dentro da língua oficial, quando "a ilusão de uma nação coesa e unificada deixa de existir" (p.20).

Para escrever o segundo artigo, OsAldrovandos Cantagaloseopreconcito lingüística J osé Luiz Fiorin se inspira em um personagem de M onteiro Lobato do conto $\mathrm{O}$ colocadordepromes o qual, vivendo em busca de erros gramaticais, deixa de perceber as belezas da linguagem. A língua como resultado de um processo histórico é o pano de fundo para a caracterização do preconceito lingüístico como fruto da "intolerância em relação à variação e à mudança" (p.27), preconceito que a própria escola e os gramáticos tratam de difundir. 0 autor focal iza fatos da mídia em que a diversidadelingüística é ridicularizada e, com bastante pertinência, examina trechos de uma 
entrevista de Pasqual eCipro N eto dada à revista VEJ A (setembro de 1997), nos quais o professor de gramática corrobora muitos preconceitos lingüísticos partindo da concepção equivocada de que a língua é homogênea e estática. A proveitando "deixas" de Pasquale na matéria, o autor discorre sobre diferenças entre a fala e a escrita e entre o português brasileiro e o europeu, e discute comentários equivocados como os seguintes: do ponto de vista da norma culta, a melhor fala é a do Rio de Janeiro e a pior é a de São Paulo; é idiota quem usa palavras em inglês no lugar de palavras equivalentes em português; em termos lingüísticos "estamos nivelados por baixo" (p.34); e a "pérola" final: o comentário do referido professor, por ocasião de um conhecido comercial da cadeia M cD onalds, de que não teria feito publicidade dos lanches mas sim divulgado a língua portuguesa... Por fim, considerando amplamente a diversidadelingüística, desqualifica com veemência a opinião dos guardiões da língua, de que "os lingüistas estão destruindo o idioma, porque para el es vale tudo" (p.35).

Tratando, na seqüência, de Estranginismos emprétimoauameca?, Pedro Garcez e A na Zilles atribuem ao empréstimo, tido como fenômeno constante no contato entre comunidades lingüísticas, marca de identidade alienígena com valores simbólicos por vezes conflitantes. O s autores organizam didaticamente o texto em torno das seguintes seções: Legitimidade e pureza; Anglicismos: A força do desejo; Diligências legislativas; Preconceito e exclusão; Diversidade invisível e vida social da linguagem. D e início, a partir do exame de uma série de palavras e expressões, demonstram não ser tarefa simples identificar o que seria português puro e como algo deixa de ser um estrangeirismo e se incorpora à língua da comunidade. A seguir, os autores argumentam que a aversão ao estrangeirismo é devida, especialmente, à presença da indústria simbólica norte-americana, portanto os empréstimos não seriam, na realidade, necessários, mas desejados face aos apelos da máquina capitalista globalizante. N a seção seguinte, trazem à tona a posição ideológica que sustenta os projetos de lei contra os estrangeirismos, destacando, com propriedade, o fato de que se apagam as diferenças internas aos grupos quando um elemento externo paira como ameaça comum, o que acaba por legitimar a concepção de que "a língua da nação se restringe à língua do poder, à norma escrita, socialmente controlável, cujos limites são definidos pelas classes dominantes" (p.46). A o abordarem a questão do preconceito e da exclusão, os autores dão visibilidade a uma série de equívocos, dentre os quais destaco: 0 de que a escrita é a essência da linguagem; o que ignora a diversidade lingüística e os proces- 
sos de variação e mudança; e o que prevêa existência de uma língua pura. Por fim, G arcez e Zilles tratam de questões como a atitude frente à língua de poder e a competição pelo acesso aos bens sociais, concluindo que a "chave invisível, mas legitimada, das práticas excludentes" é a ideologia lingüística de que somos um país monolíngüe (p.51).

A denúncia do papel da mídia na formação ena divulgação de preconceitos lingüísticos, mediante análise de cenas da novela Escrava Isaura(Rede Globo, 1976), baseada no romance de Bernardo Guimarães, e do filme americano NocaraçãodeClara- ambos tratando de questões raciais, é a tônica do texto de Fábio Lopes da Silva: Doiscasosdepreconcitolingüísticona mídia Em ambos os casos, o pretenso anti-racismo retratado pel o o quê se esvazia no comó lingüisticamente expresso. $\mathrm{N}$ a novela, 0 autor centra a atenção na forma como os personagens da Casa $\mathrm{G}$ rande se expressam, isto é, no tipo de construções gramaticais el eitas para representar a fala dos brancos (incluindo entre esses a escrava 'mocinha' I saura) - emoldurada por "todos os ss e rr da norma gramatical", e a fala dos demais escravos estilo "Tio Barnabé" (p.55); e destaca, como efeito induzido, a reprodução do mito de uma língua perfeita e intocada, tomado como realidade histórica, o que, segundo uma avaliação perspicaz do autor, leva as novelas de época a provocarem um prejuízo cultural. 0 autor projeta uma associação bastante interessante entre a chamada corrupção da língua e "uma espécie de vírus lingüístico que, na época da escravidão, permanecia confinado e controlado..." (p.57). N o filme, é recortada uma cena em que o garoto branco, dignificando a língua materna da governanta negra, dirige-se a ela em patuá jamaicano, legendado em português como "num vô fazê isso", episódio que reproduz um preconceito generalizado: o de que construções como essa se restringem a determinada camada sócio-demográfica, donde 0 autor conclui que "atribuímos a nós mesmos uma língua perfeitamente imaginária" (p.61).

$\mathrm{N}$ o quinto artigo da coletânea, Edwiges M orato aborda Asafasiasentreonomal eopatdógica da quesão(nerro)lingüística à questãoscaial, distribuindo o tema em quatro seções: A s afasias entre o normal e o patológico; 0 processo de patologização da linguagem e dos falantes; $A$ origem das "significações intoleráveis"; e 0 afásico entre o preconceito lingüísticocognitivo e a negligência social. N a primeira seção, a autora tematiza 0 preconceito contra os que apresentam alterações em suas diferentes formas de uso da linguagem em decorrência de lesão cerebral adquirida, 
enfatizando que a afasia não é apenas uma questão de saúde, ou uma questão lingüística, ou cognitiva, mas é também uma questão social; nesse sentido, considera que os limites entre a normalidade e a patologia estão vinculados à "vontade de verdade" (Foucault, 1977) de uma época, ou seja, à mentalidade e ao discurso científico vigente em uma certa sociedade. Em seguida, discorre sobre o processo de patologização, argumentando que existe um continuumsem fronteiras rígidas entre o normal e o patológico e que as doenças devem ser entendidas como a perturbação de um equilíbrio. A autora critica condutas médico-terapêuticas que se voltam para a "superação" do distúrbio de linguagem tido como um défiat (em decorrência de uma visão ideal izada delinguagem como poder racionalizante da mente), ponderando que 0 afásico, mesmo perdendo a palavra, "não perde necessariamente sua capacidade discursiva" (p.70). N a seção seguinte, a autora comenta que, numa concepção normativa de cognição e de linguagem, fatos como digressões, lapsos, hesitações, etc. são caracterizados como "significações intoleráveis" e tidos como "sintomas" em quadros de afasia, muitos deles assim rotulados por razões ideológicas e não por razões lingüísticas ou cognitivas. 0 que explica o surgimento das "significações intoleráveis" é a noção de linguagem como instrumento de acesso aos processos cognitivos internos, cuja função primordial é a comunicação à qual seríamos levados por um princípio natural de cooperação. Encerrando 0 texto, M orato apresenta uma ação exemplar contra 0 estigma e a exclusão social impostos ao afásico: a criação do Centro de Convivência de A fásicos (IEL/U nicamp), lugar onde se desmedicaliza a afasia e se enxerga "o páthos como constitutivo do normal" (p.74).

\section{0 artigo seguinte, A línga popular temrazõesqueos gamáticos desconhe} cem é assinado por H eronides M oura. $\mathrm{O}$ autor inicia o texto questionando os motivos que levam à escolha da norma culta como a representativa e "correta" da língua, e aponta, como uma das razões pel o preconceito contra a fala das classes populares, a dicotomia arraigada em nossa cultura, decorrente da correlação entre pensamento e linguagem, que opõe a "racionalidade da classe educada" à "espontaneidade pré-racional do povo" (p.76): a língua popular seria criativa, espontânea mas às vezes ilógica; a língua culta seria a melhor expressão da racional idade e da cultura - oposição que reflete a "normatização social promovida pel o Estado brasileiro" (p.77). M oura ilustra muito bem sua linha de raciocínio com uma análise criteriosa de formas de representar a comparação em português, contrapondo ao padrão normativo 'tão/tanto... quanto' e '...como', as expressões 
'que nem' e 'que só', tidas como de uso popular e possivelmente condenadas pelos normativistas pelo aparente ilogicismo presente nelas. A partir de um princípio básico da interpretação segundo o qual os interlocutores levam em conta não só o sentido inicial das expressões mas também a intenção do falante, o autor demonstra que a forma 'que nem' ('o aluno é esperto que nem o professor') simultaneamente compara e formula um julgamento sobre o termo comparado. A construção seria barrada como contradição lógica se analisada apenas quanto ao sentido inicial; mas esse uso deve ser interpretado como hiperbólico, cumprindo a função comunicativa de enfatizar que o julgamento recai sobre o termo comparado e não sobre o comparante. J á a expressão 'que só' ('o aluno é feio que só o professor') ressalta não só o julgamento feito sobre o termo comparado, mas também o caráter prototípico do termo com o qual se compara (no caso, 0 professor seria tido como um exemplo de feiúra, propriedade que é projetada sobre o aluno). Por fim, na construção elíptica ('o aluno éfeio que só'), a elipse do termo comparante é inicialmente interpretada como de um protótipo, mas a construção acaba se congel ando e funcionando como um advérbio que intensifica a propriedade comparada (= muito feio). 0 autor demonstra, assim, o perfeito funcionamento comunicativo dessas construções, que são solenemente ignoradas pel os gramáticos tradicionais.

A bordando a relação entre o Estado e a língua, no texto Brasileirofala partughês monding̈̈ismopreconcitolingüística G ilvan M üller de Oliveira enfatiza os seguintes fatos, subjacentes à concepção de que no B rasil se fala uma única língua: preconceito, desconhecimento da realidade e projeto político de construir um país monolíngüe. 0 autor coloca muito bem a questão de que ideologicamente produziu-se no B rasil o conhecimento de que se fala o português e o desconhecimento de que muitas outras línguas são faladas (por volta de 200 idiomas atualmente, sendo 170 línguas autóctones e 30 línguas alóctones). Müller de Oliveira traça um percurso histórico ricamente documentado do plurilingüismo no Brasil, da política homogeinizadora e repressiva de imposição do português como a única língua legítima e da conseqüente redução do número de línguas por um processo conhecido como "deslocamento lingüístico" (p.84). Esse processo envolveu ações como (i) a de civilizar os índios mediante a imposição da língua portuguesa e o "assassinato" especial mente da língua geral na Colônia (o que ocasionou uma verdadeira "guerra de línguas" (Calvet, 1999a)); e, posteriormente, (ii) a de nacionalizar o ensino no Estado $\mathrm{N}$ ovo, com repressão violenta às línguas alóctones, especialmente 0 al emão e o italia- 
no no sul do Brasil. 0 que o autor avalia como um dos fatos mais trágicos é que poucas vozes representativas se opuseram ao processo de homogeneização, em defesa de uma sociedade culturalmente pluralista. Evidenciando o fato de que somos hoje um país pluricultural e multilíngüe, seja pela variedade dialetal, seja pela diversidade de línguas faladas no território, Müller de Oliveira critica o espaço reduzido que ocupam na universidade tanto pesquisas sobre plurilingüismo, como projetos de uma política de garantia dos direitos lingüísticos às populações não falantes de português, e conclui defendendo, com certa dose de ousadia, a idéia de uma redefinição do "conceito de nacional idade, tornando-o plural e aberto à diversidade" (p.91).

Q uem assina o artigo seguinte éK anavillil Rajagopalan. A pós fundamentar certos argumentos que têm circulado contra a linguagem politicamente correta, o autor de Sdbreoporquêdetantoódiocontra a linguagem "politicamentecorta" conduz uma reflexão em outra direção, evidenciando situações em que a linguagem tem, sim, impacto sobre as coisas e os acontecimentos. 0 autor vale-se, inicialmente, de algumas críticas feitas por Possenti (1995), tais como a de que o problema não está na linguagem propriamente dita, mas tem méritos políticos e que é um equívoco pensar que uma substituição de palavras com diferentes conotações ideológicas poderia influenciar na diminuição dos preconceitos, e coloca a descoberto a concepção de linguagem e de mundo que recobre crenças generalizadas como a de que a linguagem serve de roupagem do pensamento, a primeira sujeita a todo tipo de desgaste, o último não; ea de que a linguagem pode nos enganar (veja-se 0 uso da linguagem figurada). A posição que daí se segue é: de que adianta mudar a linguagem se o pensamento é o mesmo? Contra-argumentando, o autor enfraquece a noção saussureana de arbitrariedade do signo ao afirmar que a grande maioria dos objetos que se nos apresentam "está presente em nossa consciência junto com a imagem que cada um deles adquiriu ao longo dos tempos" (p.99). Rajagopalan respalda sua idéia no mundo do marketing em que todo objeto é no fundo um "produto", isto é, um objeto produzido de forma tal que é impossível recuperá-lo em sua "pureza", pois os conhecemos ligados ao seu modo de apresentação; especialmente no princípio norteador do markeingde que é possível transformar o produto e não apenas a sua imagem. Ao refletir sobre a prática de determinados usos lingüísticos à luz do mundo do markeing 0 autor mobiliza o leitor a acreditar que ao trocar as palavras trocam-setambém as coisas. Então concluímos com el e: uma das maneiras 
mais eficazes (não aúnica!) de combater os preconceitos sociais é monitorar a linguagem e exercer controle sobre a fala, pois "intervir na linguagem significa intervir no mundo" (p.102).

Focalizando o caráter idealizado do português oficial que privilegia a escrita padrão, M arco Rocha e J uliana Pereira escrevem O usodeconparana dabaracãodetrabalhos derefê̂na: uma vaaina contra opreconcito argumentando que trabal hos de referência tais como gramáticas e dicionários não cumprem adequadamente sua função em virtude de discriminação da língua falada. $\mathrm{N}$ a seção subseqüente à introdução, os autores falam sobre as abordagens com base em corpus, discorrendo sobre as características ideais do mesmo: amostragem representativa, tamanho, formato legível por computador e uma referência padrão, pressupondo-se a disponibilidade do material para a comunidade lingüística em geral. A seguir, tratam do uso do coppuscontra o preconceito lingüístico, dando relevo ao papel auxiliar que a abordagem proposta pode desempenhar na elaboração de trabalhos de referência. Como evidência, apresentam o perfil de uso do verbo dar, com base na freqüência de ocorrências desse item lexical num conpusespecífico, verificando-se que grande parte desses usos corresponde a construções do tipo 'Dá só uma aguardadazinha...', uso este não contemplado num dicionário da língua portuguesa, por exemplo, a despeito de sua recorrência na fala, o que se caracteriza como um reflexo sintomático de preconceito. U ma regra léxico-gramatical de formação de sintagmas verbais que permitiria a produção de inúmeras combinações similares é, então, apresentada pelos autores. Concluindo, propõem que a noção de fre qüência seja "parte integrante dos critérios de seleção de usos a serem incluídos nos trabalhos de referência", a despeito do prestígio social dos mesmos (p.110).

0 artigo que encerra a coletânea, Língua estrangira: direitoauprivilé gio?, é de autoria de J osalba Vieira e H eronides M oura. Ao analisarem duas situações prototípicas de plurilingüismo, apoiados em documentos oficiais que legislam sobre os direitos do cidadão a uma educação bilíngüe, os autores chamam a atenção para preconceitos, por vezes camuflados, presentes em situações de aprendizado e de uso de línguas estrangeiras. As situações examinadas são jocosamente identificadas como: 0 monoglota orgulhoso e o provinciano cosmopolita; e 0 poliglota esnobe e poliglota ignorante. Ambos os casos são relacionados à metáfora do "sistema gravitacional" (Calvet, 1999b), que explica a estruturação das línguas entre si, de acordo com cada momento histórico, em termos de língua 
hipercentral, supercentral, central e periférica. H averia, de um lado, uma correspondência entrea situação do provinciano cosmopolita e a dos falantes da língua mais importante de cada período histórico; e, de outro lado, entre a situação do poliglota e a dos falantes das demais línguas, resultando a avaliação de "ignorante" ou "esnobe" do lugar ocupado por tais línguas no sistema gravitacional. Falantes poliglotas de línguas tidas como periféricas, por exemplo, não costumam ser valorizados pel o fato de serem plurilíngües (nem por eles próprios!); já aquel es que fal am línguas situadas em níveis mais próximos ao centro gravitacional, portanto de maior prestígio, tenderiam ao protótipo do poliglota esnobe, isto é, daquele que usa uma língua estrangeira com a intenção de marcar diferença cultural e não para interagir. Os autores discutem amplamente 0 preconceito que perpassa essas diferentes situações lingüísticas, ilustrando-as com relatos de casos reais e concluem dizendo que "lutar contra os diversos tipos de pre conceito lingüístico ligados ao uso de línguas estrangeiras não éuma tarefa fácil, mas saber identificá-los é um passo importante" (p.124). N esse sentido, 0 artigo cumpre perfeitamente seu papel.

Em suma, a diversidade de abordagens críticas em torno de uma temática comum prende a atenção do leitor, seja pela escolha instigante e feliz dos fenômenos lingüísticos anal isados (numa obra literária, num filme, numa novela de tel evisão, no markeing num projeto de lei, na fala de um professor de gramática, na fala de um poliglota, na fala de um afásico, enfim, na fala do povo...), seja pelo tratamento criterioso dispensado por cada autor ao texto. Acredito que o livro deve atender plenamente seu propósito, merecendo ser lido, divulgado e discutido.

Recebido em agosto de 2001

\section{REFERÊnCIAS BibliográFICAS}

BAGn O, M. 1999. Preconcitolingǘstico- oqueé comosefaz. São Paulo: Ed. Loyola.

CALVET, J.L 1999a. La gueredes langues e les pditiqueslinguistiques Paris: $\mathrm{H}$ achette Littératures.

1999b. Parr uneédogjedes langues dumonde Paris: Ed.Plon.

FoUCAULT, M. 1977. Onasimentodadínica Rio deJ aneiro: Forense U niversitária.

Possen TI, S. 1995. A linguagem politicamente correta e a análise do discurso. Revista deEstudos da Linguagm3,2: 123-140. 